\title{
Targeted Fusion Protein Therapy
}

National Cancer Institute

\section{Source}

National Cancer Institute. Targeted Fusion Protein Therapy. NCI Thesaurus. Code C15585.

Drug therapy in which the drug is a fusion protein generated by molecular biology procedures. The fusion protein combines a cell targeting moiety, such as an antibody fragment, with an effector moiety, like a bacterial toxin. 